https://helda.helsinki.fi

\title{
Is the chemistry of lawrencium peculiar?
}

\section{Xu, Wen-hua}

2016-07-14

Xu , W \& Pyykkö , P 2016 , ' Is the chemistry of lawrencium peculiar? ' , Physical Chemistry Chemical Physics , vol. 18 , no. 26 , pp. 17351-17355 . https://doi.org/10.1039/c6cp02706g

http://hdl.handle.net/10138/224395

https://doi.org/10.1039/c6cp02706g

cc_by_nc

publishedVersion

Downloaded from Helda, University of Helsinki institutional repository.

This is an electronic reprint of the original article.

This reprint may differ from the original in pagination and typographic detail.

Please cite the original version. 


\section{Is the chemistry of lawrencium peculiar? $\dagger$}

\begin{abstract}
Cite this: Phys. Chem. Chem. Phys., 2016, 18, 17351

Received 22nd April 2016,

Accepted 8th June 2016

DOI: $10.1039 / \mathrm{c} 6 \mathrm{cp} 02706 \mathrm{~g}$

www.rsc.org/pccp

It is explicitly verified that the atomic $7 p^{1}$ ground-state configuration of $L r$ originates from relativistic effects. Without relativity one has $6 d^{1}$. All three ionization potentials $I_{1-3}$ of $L r$ resemble those of Lu. Simple model studies on mono- and trihydrides, monocarbonyls or trichlorides suggest no major chemical differences between Lr and the lanthanides.
\end{abstract}

\section{Introduction}

The periodic table is about chemistry. The group is related to the number of valence electrons and the period is related to the number of nodes in the radial functions of these electrons. In lawrencium, ${ }_{103} \mathrm{Lr}$, counting the filled $5 \mathrm{f}$ shell as the 'core', there are three valence electrons. It had been debated for some time, whether they are $7 s^{2} 6 d^{1}$ or $7 s^{2} 7 p_{1 / 2}{ }^{1}$, until both an experiment ${ }^{1}$ and also the latest calculations supported the latter alternative. That $7 \mathrm{p}^{1}$ atomic ground state was first surmised by Brewer ${ }^{2}$ and first calculated by Desclaux and Fricke. ${ }^{3}$ Large MCDF calculations by Zou and Froese Fischer ${ }^{4}$ support the $5 d^{1}$ and $7 p^{1}$ ground states for $\mathrm{Lu}$ and $\mathrm{Lr}$, respectively, and yield very different oscillator strengths. For Lr, however, they are not yet experimentally confirmed.

This does not yet settle the question on the chemical behaviour. If all three valence electrons are formally ionized away, in an $\operatorname{Lr}(\mathrm{III})$ compound, lawrencium clearly belongs to Group 3 in Period 7, and nothing unexpected has happened in its chemistry.

The three first ionization potentials of Lr are compared with those of La-Lu in Fig. 1. They are quite similar, especially with Lu. Therefore the ionic chemistry of Lr could be expected to be similar to that of the lanthanides.

\footnotetext{
${ }^{a}$ Key Laboratory of Synthetic and Natural Functional Molecule Chemistry of the Ministry of Education, College of Chemistry and Molecular Science, Northwest University, 710127 Xi'an, China. E-mail: xuwenhua.qf@gmail.com

${ }^{b}$ Department of Chemistry, University of Helsinki, POB 55 (A. I. Virtasen aukio 1), o0014 Helsinki, Finland. E-mail: Pekka.Pyykko@helsinki.fi

$\dagger$ Electronic supplementary information (ESI) available. See DOI: 10.1039/c6cp02706g
}

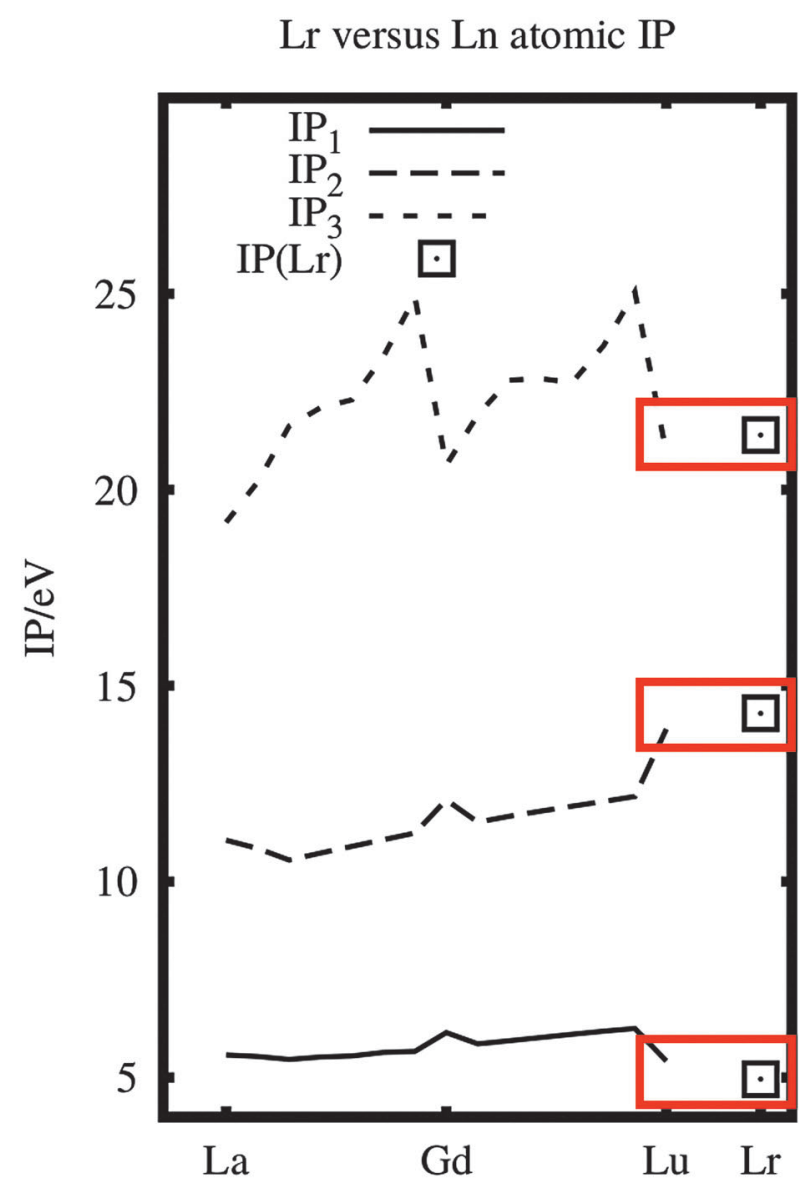

Fig. 1 The ionization potentials of $\mathrm{La}-\mathrm{Lu}$ (experimental data ${ }^{5}$ ) and $\mathrm{Lr}$ (experimental and calculated $\mathrm{IP}_{1} \cdot{ }^{1}$ calculated $\mathrm{IP}_{2,3}{ }^{6}$ ). Note the similarity of Lu and Lr.

Experimentally this is what happened, see Brüchle et al., ${ }^{7}$ Hoffman et al. ${ }^{8}$ and Scherer et al., ${ }^{9}$ all in 1988. Brüchle and Hoffman found that $\operatorname{Lr}(\mathrm{III})$ had a similar elution behaviour to the latter $\operatorname{Ln}($ III) and Scherer found no evidence for a possible reduction to lower oxidation states than $\operatorname{Lr}($ III) in aqueous 
solution. Recently, in reductive surroundings, all the divalent lanthanide oxidation states $\operatorname{Ln}\left(\right.$ II) have also been obtained. ${ }^{10}$ These divalent lanthanide, $\mathrm{Ln}(\mathrm{II})$, compounds are mostly $5 \mathrm{~d}^{1}$. No such experiments exist on Lr.

Calculations suggest that the free-atom $\operatorname{Lr}(\mathrm{I})$ and $\operatorname{Lr}(\mathrm{II})$ are $7 \mathrm{~s}^{2}$ and $7 \mathrm{~s}^{1}$, respectively, ${ }^{5,6,11}$ in contrast to the quoted $5 \mathrm{~d}^{1}$ for $\operatorname{Ln}$ (II) in compounds. ${ }^{10}$ The stabilisation of the $7 \mathrm{~s}$ shell in Group 3 can be compared with that of the $6 \mathrm{~s}$ shell in Group 13, which contributes to the chemical difference between indium and thallium, having the main oxidation states $\mathrm{In}$ (III) and $\mathrm{Tl}(\mathrm{I}$ ), respectively. Similarly, for lead, the relativistic stabilization of the $6 \mathrm{~s}$ shell favours the divalent $\mathrm{Pb}(\mathrm{II})$ state in $\mathrm{PbO}$ or $\mathrm{PbSO}_{4}$ and destabilizes the $\mathrm{Pb}$ (Iv) state in $\mathrm{PbO}_{2}$, thereby explaining most of the voltage of the lead battery. ${ }^{12}$ In these main-group cases the relativistic stabilization of an ns shell leads to different main oxidation states in Periods 5 and 6. One possibility considered here is whether one could have a similar change between lanthanides and actinides. Recall that the relativistic stabilization of valence s shells down the same column increases as $Z^{2}$, where $Z$ is the nuclear charge.

\section{Atomic results}

We first verify the relativistic origin of the ground-state change from $6 d^{1}$ to $7 p^{1}$, see Table $\mathrm{S} 1$ in the ESI. $\dagger$ Compared with the non-relativistic results, Dirac-Fock (DF) shifts down the relative energy of $(n+1){ }^{2} \mathrm{P}$ to $n^{2} \mathrm{D}$ by nearly $3 \mathrm{eV}$, and changes the ground state configuration. The relativistic effect is so large that already DF-level evidence makes sense. MCDF results were reported by Fritzsche et al. ${ }^{13}$

The calculated orbital energies for $\mathrm{Tl}$ and $\mathrm{Lr}$ atoms are shown in Fig. 2. It is seen that the relativistic stabilization of the $\mathrm{Tl} 6 \mathrm{~s}$ shell is substantial, making its energy comparable to the ligand orbital energy (here $\mathrm{H}$ ). In contrast, the $\mathrm{Lr}$ 7s orbital energy is small, despite a larger $Z$.

Does the atomic ground state matter in chemistry? As seen in Fig. 2, the valence orbital energies of the electropositive element Lr are small and hence in compounds these electrons, whether 7s, 6d or 7p, will largely go away, anyway. Group 13 is more electronegative ${ }^{14}$ than Group 3.

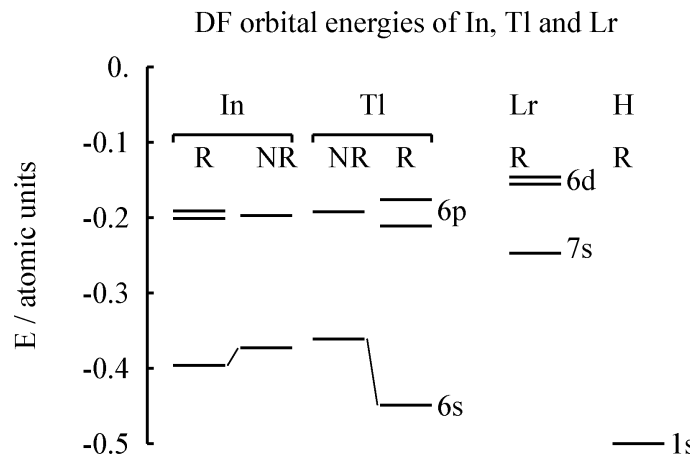

Fig. 2 The calculated relativistic (R) and non-relativistic (NR) Dirac-Fock orbital energies of neutral In, Tl and Lr atoms. For lawrencium, the electron configuration $7 s^{2} 6 d^{1}$ is assumed. Values from Desclaux. ${ }^{15}$
Why is Lr, like other lanthanides and actinides, so electropositive? A broad-brush explanation could be that they all belong to Group 3 and the electronegativities in the Periodic table increase from left to right (from Group 1 to Group 18), probably due to increasing partial screening by the fellow valence electrons.

\section{Molecular results}

\subsection{Hydrides}

We first consider the simple hydride models and calculate the reaction energy, $\Delta E$ for the model reaction

$$
\mathrm{MH}_{3} \rightarrow \mathrm{MH}+\mathrm{H}_{2}
$$

for $\mathrm{M}=\mathrm{Lr}, \mathrm{Lu}$, In and Tl. As seen in Table 1 , this $\Delta E$ is negative for thallium which clearly prefers to be $\mathrm{Tl}(\mathrm{I})$, and positive for the other four metals, which prefer being M(III), including $\operatorname{Lr}(\mathrm{III})$. $\mathrm{Tl}(\mathrm{I})$ is an example of the relativistic $6 \mathrm{~s}^{2}$ inert pair.

The structural parameters are given in Table 2 .

\subsection{Monocarbonyls}

We then compare LrCO with the series LnCO, Ln $=$ La-Lu, studied both experimentally and theoretically by $\mathrm{Xu}$ et al. ${ }^{19}$ There the three last members $\mathrm{Ln}=\mathrm{Tm}, \mathrm{Yb}$, and Lu which could not be made, and they had theoretically weak bonds, for $\mathrm{Lu}$ with a $\sigma^{2} \pi^{1}$ valence configuration. We now find that $\operatorname{Lr}$ behaves just like Lu, which further supports putting it under $\mathrm{Lu}$ in the

Table 1 Reaction energies $\Delta E$ for $\mathrm{MH}_{3} \rightarrow \mathrm{MH}+\mathrm{H}_{2}$ (1) (in eV). The In and $\mathrm{Tl}$ results are from Vest et al. ${ }^{16}$ The other results from the present work. As seen from Table 2, $\mathrm{LrH}_{3}$ is $\mathrm{C}_{3 \mathrm{v}}$

\begin{tabular}{llccc}
\hline $\mathrm{M}$ & $\mathrm{HF}$ & $\mathrm{MP} 2$ & $\mathrm{CCSD}(\mathrm{T})$ & $\mathrm{DFT}$ \\
\hline $\mathrm{Lr}$ & +0.17 & -0.07 & +0.10 & +0.39 \\
$\mathrm{Lr}^{a}$ & +0.14 & -0.03 & +0.13 & \\
$\mathrm{Ac}$ & +0.44 & +0.10 & +0.25 & +0.89 \\
$\mathrm{Lu}$ & +0.88 & +0.66 & +0.72 & +0.91 \\
$\mathrm{In}$ & & & +0.07 & \\
$\mathrm{Tl}$ & & & -0.72 &
\end{tabular}

${ }^{a}$ Triple-zeta basis. Other wave function methods use the double-zeta basis.

Table 2 Geometrical two-component (2c) DFT parameters of $\mathrm{MH}, \mathrm{MH}_{2}$, $\mathrm{MH}_{3}, \mathrm{MCO}, \mathrm{MCl}_{3}$ and $\left[\left(\mathrm{Cp}^{\prime}\right)_{3} \mathrm{M}\right]^{-}(\mathrm{M}=\mathrm{Lu}, \mathrm{Lr})$. Lengths in $\AA$, angles in degrees

\begin{tabular}{llll}
\hline Molecule & Symmetry & Bond length & Bond angle \\
\hline LuH & Linear & 1.895 & \\
LrH & Linear & 1.960 & \\
$\mathrm{LuH}_{2}$ & $C_{2 \mathrm{v}}$ & 1.915 & 113.5 \\
$\mathrm{LrH}_{2}$ & $C_{2 \mathrm{v}}$ & 1.954 & 110.6 \\
& $C_{2 \mathrm{v}}{ }^{2}$ & 2.015 & 117.5 \\
$\mathrm{LuH}_{3}$ & $C_{3 \mathrm{v}}$ & 1.921 & 112 \\
$\mathrm{LrH}_{3}$ & $C_{3 \mathrm{v}}$ & 1.940 & 107 \\
$\mathrm{LuCO}^{\mathrm{LrCO}}$ & Linear & $2.297(\mathrm{Lu}-\mathrm{C}), 1.167$ & 180 \\
$\mathrm{LuCl}_{3}$ & Linear & $2.384(\mathrm{Lr}-\mathrm{C}), 1.169$ & 180 \\
$\mathrm{LrCl}_{3}$ & $D_{3 \mathrm{~h}}$ & 2.394 & 120 \\
{$\left[\left(\mathrm{Cp}^{\prime}\right)_{3} \mathrm{Lu}\right]^{-}$} & $C_{3 \mathrm{v}}$ & 2.424 & 113 \\
{$\left[\left(\mathrm{Cp}^{\prime}\right)_{3} \mathrm{Lr}\right]^{-}$} & $C_{1}$ & $2.635^{b, c}$ &
\end{tabular}

${ }^{a}$ Ref. 17. ${ }^{b}$ Ref. $10{ }^{c}$ Shortest M-C. 
Table 3 Population analysis of $\mathrm{LrH}_{1} \mathrm{LrH}_{2}, \mathrm{LrH}_{3}$, LuCO and $\mathrm{LrCO}$. P: projection analysis:; ${ }^{18} \mathrm{M}$ : Mulliken population. G: Four-component Hamiltonian with the DZ Gaussian basis set; S: two-component Hamiltonian with the DZ Slater basis set

\begin{tabular}{|c|c|c|c|}
\hline Mol. & Type & Functional & Valence population \\
\hline$\overline{\mathrm{LuH}}$ & $\mathrm{M}, \mathrm{S}$ & PBE & Lu $6 \mathrm{~s}(1.77) 5 \mathrm{~d}(0.68) 6 \mathrm{p}(0.20)$ H $1 \mathrm{~s}(1.34)$ \\
\hline & $\mathrm{P}, \mathrm{G}$ & CAMB3LYP & Lr $7 \mathrm{~s}(1.80) 6 \mathrm{~d}(0.53) 7 \mathrm{p}(0.27)$ H $1 \mathrm{~s}(1.34)$ \\
\hline & $\mathrm{M}, \mathrm{S}$ & PBE & $\operatorname{Lr} 7 \mathrm{~s}(1.83) 6 \mathrm{~d}(0.61) 7 \mathrm{p}(0.21)$ H $1 \mathrm{~s}(1.34)$ \\
\hline $\mathrm{LuH}_{2}$ & $\mathrm{M}, \mathrm{S}$ & PBE & Lu $6 \mathrm{~s}(1.03) 5 \mathrm{~d}(0.96) 6 \mathrm{p}(0.27) \mathrm{H} 1 \mathrm{~s}(1.35)$ \\
\hline & $\mathrm{M}, \mathrm{S}$ & PBE & Lu $6 \mathrm{~s}(0.66) 5 \mathrm{~d}(0.97) 6 \mathrm{p}(0.25) \mathrm{H} 1 \mathrm{~s}(1.36)$ \\
\hline \multirow[t]{2}{*}{$\mathrm{LrH}_{3}$} & $\mathrm{P}, \mathrm{G}$ & PBE & Lr $7 \mathrm{~s}(0.89) 6 \mathrm{~d}(1.05) 7 \mathrm{p}(0.25) \mathrm{H} 1 \mathrm{~s}(1.26)$ \\
\hline & $\mathrm{M}, \mathrm{S}$ & PBE & Lr $7 \mathrm{~s}(0.84) 6 \mathrm{~d}(0.94) 7 \mathrm{p}(0.17) \mathrm{H} 1 \mathrm{~s}(1.34)$ \\
\hline $\mathrm{LuCO}$ & $\mathrm{M}, \mathrm{S}$ & PBE & Lu $6 \mathrm{~s}(1.77) 5 \mathrm{~d}(0.75) 6 \mathrm{p}(0.18)$ C $2 \mathrm{sp}(3.90)$ O $2 \mathrm{sp}(6.25)$ \\
\hline LrCO & $\mathrm{M}, \mathrm{S}$ & PBE & Lr $7 \mathrm{~s}(1.82) 6 \mathrm{~d}(0.66) 7 \mathrm{p}(0.20) \mathrm{C} 2 \mathrm{sp}(3.91)$ O $2 \mathrm{sp}(6.27)$ \\
\hline
\end{tabular}

Table 4 Natural electron configurations of $\mathrm{LrH}_{1} \mathrm{LrH}_{3}, \mathrm{LuCO}$ and $\mathrm{LrCO}$. The density matrices are from ZORA1c and PBE calculations. At this level, an NBO was available

\begin{tabular}{ll}
\hline Mol. & Natural electron configuration \\
\hline $\mathrm{LrH}$ & {$[$ core]7s $(1.92) 6 \mathrm{~d}(0.34) 7 \mathrm{p}(0.04)$} \\
$\mathrm{LrH}_{3}$ & {$[$ core]7s $(0.84) 6 \mathrm{~d}(0.67) 7 \mathrm{p}(0.01)$} \\
$\mathrm{LrCO}$ & {$[$ core]7s $(1.93) 6 \mathrm{~d}(0.51) 7 \mathrm{p}(0.05)$} \\
$\mathrm{LuCO}$ & {$[$ core]6s $(1.90) 5 \mathrm{~d}(0.56) 6 \mathrm{p}(0.06)$} \\
\hline
\end{tabular}

Periodic table. At the CCSD(T) level, $\mathrm{LrCO}$ is $1.0 \mathrm{eV}$ below $\mathrm{Lr}+\mathrm{CO}$, while $\mathrm{LuCO}$ is $0.77 \mathrm{eV}$ below $\mathrm{Lu}+\mathrm{CO}$. The attempts to produce $\mathrm{LuCO}^{19}$ nevertheless failed.

Population analyses are shown in Tables 3-5. Projection analysis is stable regarding different types of functionals. In this study, Mulliken populations agree well with the projection analysis. There is a high correlation between Lu and Lr electronic configurations in all the hydrides and carbonyls.

The C-O stretching frequencies are 1897 and $1921 \mathrm{~cm}^{-1}$ for LrCO and LuCO, respectively. The valence orbitals of LuCO and LrCO are compared in Fig. 3 and found to be very similar. We conclude that although the p populations strongly depend on the method of calculation, Mulliken, NBO (Natural Bond Orbital) or projection, the results for Lu $6 \mathrm{p}$ and $\mathrm{Lr} 7 \mathrm{p}$ are closely similar.

Table 5 Frontier HF orbitals of $\mathrm{LrH}_{1} \mathrm{LrH}_{3}, \mathrm{LuCO}$ and $\mathrm{LrCO}$. The first two closed-shell molecules are computed using an X2C Hamiltonian, while the latter two open-shell ones use a scalar relativistic ECP. Energies in eV. Mulliken populations in \%. $\mathrm{h}=\mathrm{HOMO}$. At the spin-orbit-split two-component level, only Mulliken population analysis was available

\begin{tabular}{|c|c|c|c|}
\hline Mol. & Orb. & Energy & Populations \\
\hline \multirow[t]{2}{*}{ LrH } & $\mathrm{h}$ & -6.31 & Lr s(64), Lr p(14), Lr d(13), H s(7) \\
\hline & h-1 & -10.61 & Lr s (28), Lr p (5), Lr d(10), H s(56) \\
\hline \multirow{3}{*}{$\mathrm{LrH}_{3}$} & $\mathrm{~h}$ & -9.65 & $\operatorname{Lr} \mathrm{p}(8), \operatorname{Lr} \mathrm{d}(26), \mathrm{H} \mathrm{s}(67)$ \\
\hline & h-1 & -10.16 & Lr p(14), Lr d(18), H s(65) \\
\hline & h-2 & -11.65 & Lr s(39), H s(55) \\
\hline \multirow[t]{2}{*}{ LrCO } & $\mathrm{h}$ & -6.31 & Lr p(10), Lr d(26), C p(47), O p(16) \\
\hline & h-1 & -6.92 & $\operatorname{Lr} \mathrm{s}(86), \operatorname{Lr} \mathrm{p}(7), \operatorname{Lr} \mathrm{d}(6)$ \\
\hline \multirow[t]{2}{*}{ LuCO } & $\mathrm{h}$ & -6.72 & Lu p(11), Lu d(23), C p(44), O p(15) \\
\hline & h-1 & -6.38 & Lu s(84), Lu p(8), Lu d(8) \\
\hline
\end{tabular}
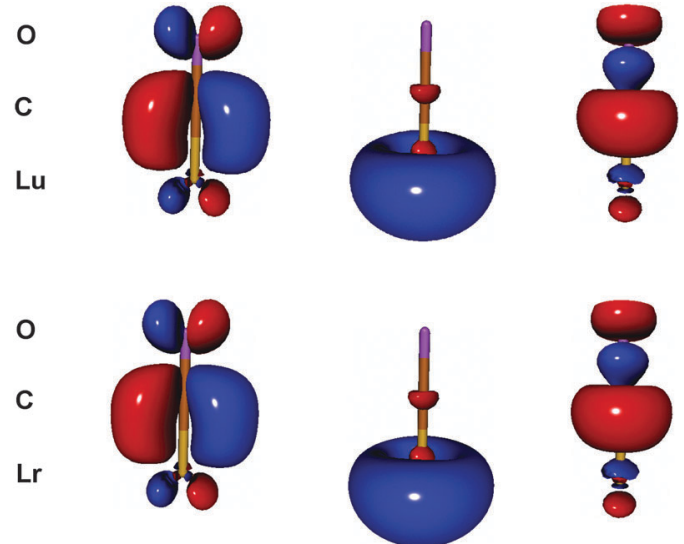

Fig. 3 The $\mathrm{HF} \pi$ (HOMO), $\sigma(\mathrm{HOMO}-1)$ and $\sigma$ donation molecular orbitals (from left to right) of the monocarbonyls LuCO and LrCO with ECP. They are fairly similar to each other. ${ }^{19}$ Isodensity value $=0.05$ a.u.

\subsection{Lawrencium trichloride and a divalent complex}

One feature of the bonding in lanthanide chlorides is the $\mathrm{p} \pi-\mathrm{d} \pi$ bond. It is also observed in $\mathrm{LrCl}_{3}$. Note that unlike in $D_{3 \mathrm{~h}} \mathrm{LuCl}_{3}$, the geometry of $\mathrm{LrCl}_{3}$ is $C_{3 \mathrm{v}}$, with an out-of-plane vibrational frequency of only $48 \mathrm{~cm}^{-1}$. For the bonding molecular orbitals, see Fig. 4 .

In recent years, one breakthrough in lanthanide chemistry is that divalent complexes were synthesized and characterized for all lanthanides. We now studied an Lr complex with the same ligand as that for $\mathrm{Ln}$, i.e. $\mathrm{C}_{5} \mathrm{H}_{4} \mathrm{SiMe}_{3}\left(\mathrm{Cp}^{\prime}\right)$. Experimentally, a potassium atom in a crown ether ${ }^{10}$ functioned as the counterion of $\left[\operatorname{Ln}\left(\mathrm{Cp}^{\prime}\right)_{3}\right]^{-}$.

A stable geometry was found for this complex anion. The electronic structure is similar to that of $\mathrm{Lu}$. The metal configuration is $6 \mathrm{~d}^{1}$. Spin-orbit effects were included in the calculation. As seen from Fig. 5, this HOMO is a $\mathrm{d}^{1}$ orbital on Lr.

The structures of all systems are given in the ESI. $\dagger$

\section{Relation to the periodic table}

Three different choices can be outlined for the f-element rows:

1. Fourteen-element rows, La-Yb and Ac-No. Put Lu and Lr in Group 3. Chosen by Jensen ${ }^{20}$ and currently Wikipedia. 


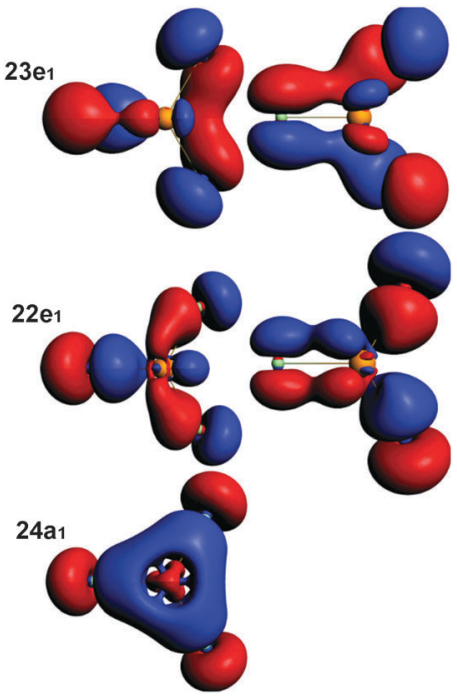

Fig. 4 The molecular orbitals of the $C_{3 v} \mathrm{LrCl}_{3}$ with $3 p(\mathrm{Cl})-6 \mathrm{~d}(\mathrm{Lr})$ bonds They are fairly similar to those of $\mathrm{LuCl}_{3}$. The 'e' orbitals are doubly degenerate and both components are shown. Isodensity value $=0.05$

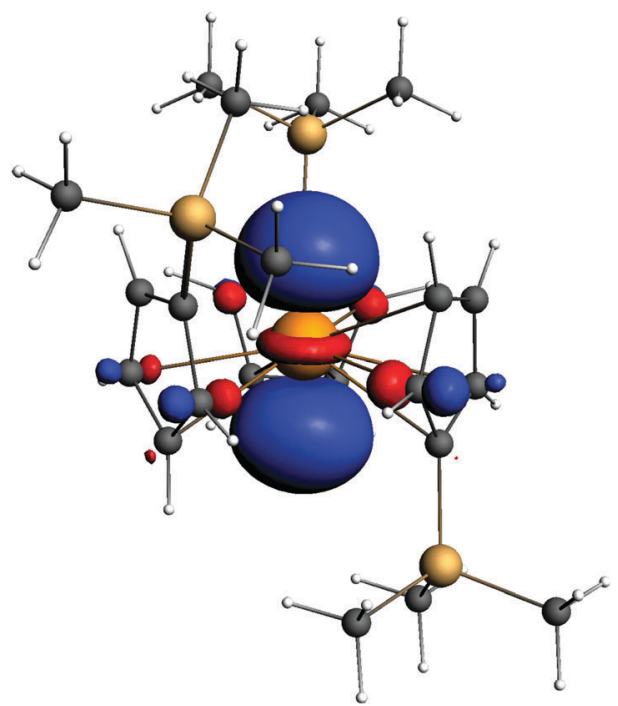

Fig. 5 The HOMO orbital of $\left[\left(C p^{\prime}\right)_{3} L r\right]^{-}$. Isodensity value $=0.05$ a.u.

2. Fourteen-element rows, Ce-Lu and Th-Lr. Put La and Ac in Group 3. Chosen by Lavelle, ${ }^{21}$ the Royal Society of Chemistry and the American Chemical Society.

3. Fifteen-element rows, La-Lu and Ac-Lr. This includes $\mathrm{f}^{0}$ among the $\mathrm{f}^{1}$ to $\mathrm{f}^{14}$ series. All elements are mostly trivalent. Their ionic and covalent ${ }^{22}$ radii form a continuous series. Now chosen by IUPAC $^{23}$ and by us. To us the atomic ground state is less important than the chemical bonding, in the systems so far considered.

\section{Computational details}

The geometries were optimized at the ZORA $2 \mathrm{c}^{24}$ level, DFT (PBE

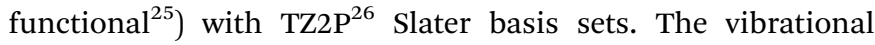

frequencies were obtained to confirm the minima. However, $\left[\left(\mathrm{Cp}^{\prime}\right)_{3} \mathrm{Lr}\right]^{-}$was optimized with the TPSSh functional ${ }^{27,28}$ to compare with the published $\left[\left(\mathrm{Cp}^{\prime}\right)_{3} \mathrm{Lu}\right]^{-}$results. Solvent effects were considered by the COSMO model ${ }^{29}$ with tetrahydrofurane (THF) parameters. For more details, see the computational part of ref. 10. ADF $2016^{30,31}$ and Turbomole $7.02^{32}$ packages were used. To calculate more accurate energetics, the two-component (2c)-MP2 $2^{33,34}$ and (2c)-CCSD(T) ${ }^{35}$ as implemented in Dirac $15.0,{ }^{36}$ and $\operatorname{CCSD}(\mathrm{T})$ implemented in Molpro 2015.1 ${ }^{37,38}$ were employed. The basis sets are Dyall all-electron double zeta ${ }^{39}$ and ECP from the Stuttgart/Cologne group, ${ }^{40,41}$ respectively.

\section{Conclusion}

All three ionization potentials of the lawrencium atom resemble those of the lanthanides, especially lutetium. Despite the different atomic ground states of $\mathrm{d}^{1}$ and $\left(\mathrm{p}^{*}\right)^{1}$ for Lu and Lr, respectively, their chemical behaviour in the present systems is found to be similar. Nothing prevents one from keeping a fifteen-element trivalent actinide row Ac-Lr, under the trivalent lanthanide row La-Lu. This entirely avoids the issues arising from fourteenelement rows. ${ }^{20,21}$

\section{Acknowledgements}

This project is supported by grant 275845 from The Academy of Finland to Professor Dage Sundholm. WHX thanks the China Scholarship Council and the Northwest University, Xi'an for a leave of absence and support (No. 13NW24). CSC, Espoo, Finland, provided both software and computer time. PP is grateful to the Magnus Ehrnrooth Foundation for a travel grant.

\section{References}

1 T. K. Sato, M. Asai, A. Borschevsky, T. Stora, N. Sato, Y. Kaneya, K. Tsukada, Ch. E. Düllmann, K. Eberhardt, E. Eliav, S. Ichikawa, U. Kaldor, J. V. Kratz, S. Miyashita, Y. Nagame, K. Ooe, A. Osa, D. Renisch, J. Runke, M. Schädel, O. ThörlePospiech, A. Toyoshima and N. Trautmann, Nature, 2015, 520, 209-211.

2 L. Brewer, J. Opt. Soc. Am., 1971, 61, 1101-1111.

3 J. P. Desclaux and B. Fricke, J. Phys., 1980, 41, 943-946.

4 Y. Zou and C. Froese Fischer, Phys. Rev. Lett., 2002, 88, 183001. 5 A. Kramida, Yu. Ralchenko, J. Reader and the NIST ASD Team, Atomic Spectra Database (ver. 5.2), 2016, v 5.2.

6 X.-Y. Cao and M. Dolg, Mol. Phys., 2003, 101, 961-969.

7 W. Brüchle, M. Schädel, U. W. Scherer, J. V. Kratz, K. E. Gregorich, D. Lee, M. Nurmia, R. M. Chasteler, H. L. Hall, R. A. Henderson and D. C. Hoffman, Inorg. Chim. Acta, 1988, 146, 267-276.

8 D. C. Hoffman, R. A. Henderson, K. E. Gregorich, D. A. Bennett, R. M. Chasteler, C. M. Chasteler, C. M. Gannett, H. L. Hall, D. M. Lee, M. Nurmia, S. Cai, R. Agarwal, A. W. Charlop, Y. Y. Chu, G. T. Seaborg and R. J. Silva, J. Radioanal. Nucl. Chem., 1988, 124, 135-144. 
9 U. W. Scherer, J. V. Kratz, M. Schädel, W. Brüchle, K. E. Grigorich, R. A. Henderson, D. Lee, M. Nurmia and D. C. Hoffman, Inorg. Chim. Acta, 1988, 146, 249-254.

10 M. R. MacDonald, J. E. Bates, J. W. Ziller, F. Furche and W. J. Evans, J. Am. Chem. Soc., 2013, 135, 9857-9868.

11 E. Eliav, U. Kaldor and Y. Ishikawa, Phys. Rev. A: At., Mol., Opt. Phys., 1995, 52, 291-296.

12 R. Ahuja, A. Blomqvist, P. Larsson, P. Pyykkö and P. ZaleskiEjgierd, Phys. Rev. Lett., 2011, 106, 018301.

13 S. Fritzsche, C. Z. Dong, F. Koike and A. Uvarov, Eur. Phys. J. D, 2007, 45, 107-113.

14 L. Pauling, The Nature of the Chemical Bond, Cornell Univ. Press, Ithaca, NY, 3rd edn, 1960.

15 J. P. Desclaux, At. Data Nucl. Data Tables, 1973, 12, 311-406. 16 B. Vest, K. Klinkhammer, C. Thierfelder, M. Lein and P. Schwerdtfeger, Inorg. Chem., 2009, 48, 7953-7961.

17 K. Balasubramanian, J. Chem. Phys., 2002, 116, 3568-3575.

18 S. Dubillard, J.-B. Rota, T. Saue and K. Faegri, J. Chem. Phys., 2006, 124, 154307.

19 W.-H. Xu, X. Jin, M.-H. Chen, P. Pyykkö, M.-F. Zhou and J. Li, Chem. Sci., 2012, 3, 1548-1554.

20 W. B. Jensen, Found. Chem., 2015, 17, 23-31.

21 L. Lavelle, J. Chem. Educ., 2008, 85, 1482-1483.

22 P. Pyykkö, J. Phys. Chem. A, 2015, 119, 2326-2337.

23 IUPAC, iupac.org/what-we-do/periodic-table-of-elements/, Downloaded 4 May 2016.

24 E. van Lenthe, E. J. Baerends and J. G. Snijders, J. Chem. Phys., 1993, 99, 4597-4610.

25 J. P. Perdew, K. Burke and M. Ernzerhof, Phys. Rev. Lett., 1996, 77, 3865-3868.

26 E. van Lenthe and E. J. Baerends, J. Comput. Chem., 2003, 24, 1142-1156.

27 J. Tao, J. P. Perdew, V. N. Staroverov and G. E. Scuseria, Phys. Rev. Lett., 2003, 91, 146401.
28 V. Staroverov, G. Scuseria, J. Tao and J. Perdew, J. Chem. Phys., 2003, 119, 12129-12137.

29 A. Klamt and G. Schüürmann, J. Chem. Soc., Perkin Trans. 2, 1993, 799-805.

30 ADF2016, SCM, Theoretical Chemistry, Vrije Universiteit, Amsterdam, The Netherlands, http://www.scm.com.

31 G. te Velde, F. M. Bickelhaupt, E. J. Baerends, C. Fonseca Guerra, S. J. A. van Gisbergen, J. G. Snijders and T. Ziegler, J. Comput. Chem., 2001, 22, 931-967.

32 TURBOMOLE V7.02 2015, a development of University of Karlsruhe and Forschungszentrum Karlsruhe $\mathrm{GmbH}$, 1989-2007, TURBOMOLE GmbH, since 2007; available from http://www.turbomole.com.

33 S. Knecht and T. Saue, X2Cmod: A modular code for ExactTwo-Component Hamiltonian Transformations. 2010-2013 with contributions from M. Ilias, H. J. Aa. Jensen and M. Repisky, 2010.

34 J. K. Laerdahl, T. Saue and K. Faegri Jr, Theor. Chem. Acc., 1997, 97, 177-184.

35 L. Visscher, T. J. Lee and K. G. Dyall, J. Chem. Phys., 1996, 105, 8769-8776.

36 R. Bast, T. Saue, L. Visscher, H. J. A. Jensen et al., DIRAC, a relativistic $a b$ initio electronic structure program, Release DIRAC15 (2015), see http://www.diracprogram.org.

37 H.-J. Werner, P. Knowles, G. Knizia, F. Manby and M. Schütz, et al. MOLPRO, version 2015.1, a package of ab initio programs, 2015, see http://www.molpro.net.

38 H.-J. Werner, P. J. Knowles, G. Knizia, F. R. Manby and M. Schütz, Wiley Interdiscip. Rev.: Comput. Mol. Sci., 2012, 2, 242-253.

39 K. G. Dyall, Theor. Chem. Acc., 2012, 131, 1-11.

40 X.-Y. Cao and M. Dolg, J. Chem. Phys., 2001, 115, 7348-7355.

41 X.-Y. Cao, M. Dolg and H. Stoll, J. Chem. Phys., 2003, 118, 487-496. 